\title{
Non-functional adrenal gland ganglioneuroma: case report
}

\author{
Rashmi D. Patel ${ }^{1 *}$, Aruna V. Vanikar ${ }^{1}$ and Hargovind L. Trivedi ${ }^{2}$ \\ *Correspondence: rashmi381@yahoo.co.in \\ ${ }^{1}$ Department of Pathology, Laboratory Medicine and Transfusion Services and Immunohematology, G. R. Doshi and K. M. Mehta \\ Institute Of Kidney Diseases \& Research Centre (IKDRC)- Dr. H.L. Trivedi Institute Of Transplantation Sciences (ITS), Civil Hospital \\ Campus, Asarwa, Ahmedabad- 380016, Gujarat, India. \\ ${ }^{2}$ Department of Nephrology and Clinical Transplantation, G.R. Doshi and K.M. Mehta Institute of Kidney diseases And Research \\ Centre and Dr. H.L. Trivedi Institute of Transplantation Sciences, Ahmedabad, India.
}

\begin{abstract}
Background: Adrenal ganglioneuromas in young adults are rare and ill-understood. We report an incidentally detected adrenal gland tumor diagnosed as ganglioneuroma (mature type).

Methods and result: Asian 33 years old male who presented with vomiting and epigastric pain for 2 months. USG and CTabdomen revealed well-defined rounded hypo-dense non-enhancing homogenous mass of left adrenal gland. Histopathology examination revealed a well-encapsulated benign tumor of mature ganglion cells and Schwann-like cells arranged in fascicles, staining strongly with NSE and s-100 proteins, with adjacent unremarkable adrenal cortex and medulla.

Conclusion: Ganglioneuromas (GN) of adrenal gland in adults are very rare and can have serendipitious presentation. We describe such a non-functional adrenal GN in a young male.
\end{abstract}

Keywords: Adrenal gland ganglioneuroma, cholecystitis, ganglion cells, catecholamines, neuroblastoma, mediastinum

\section{Introduction}

Neuroblastic tumors arise from neural crest cells and encompass a spectrum ranging from neuroblastoma, an undifferentiated malignant tumor to ganglioneuroma $(\mathrm{GN})$, a well differentiated benign neoplasm, which consists of mature Schwann cells, ganglion cells and nerve fibers. GN rarely occurs in the adrenal gland, hence diagnosis is usually difficult [1]. GN do not secrete excess catecholamines or steroid hormones and are often clinically silent and asymptomatic even if they are large [2]. Detection of this tumor has increased with availability of imaging procedures like ultrasonography (USG)/computed tomography (CT)/magnetic resonance imaging (MRI) however histopathology still remains the gold standard for final diagnosis and ruling out a malignant tumor $[3,4]$.

We describe a case of an asymptomatic, non-functional adrenal GN incidentally diagnosed in young adult.

\section{Case presentation}

A 33 years old man presented with complaints of vomiting and epigastric pain of 2 months duration. There was no flank pain, fever, hematuria, pyuria or weight loss. Past/ family history was non-contributory. On examination, he was well-built, afebrile, with pulse $96 / \mathrm{min}$, blood pressure, $160 / 90 \mathrm{mmHg}$ and body-mass index was $31.8 \mathrm{~kg} / \mathrm{m}^{2}$. Systemic examination was unremarkable. Abdomen was soft without organomegaly. Routine lab investigations were unremarkable with normal blood sugar, hematology, liver, and renal function profile. Endocrine tests, including cortisol, adrenocorticotropin hormone
(ACTH) levels, 24 hours urinary catecholamines were within normal ranges. USG revealed unremarkable liver, spleen and pancreas; gall bladder (GB) was distended with $4 \mathrm{~mm}$ sized echogenic shadow partially occupying the lumen reported as calculus/sludge. Both kidneys were unremarkable. A hypoechoic area with well-defined margins measuring $8.1 \times 8 \mathrm{~cm}$ was seen over left supra-renal area displacing left kidney (LK) laterally. CT-abdomen revealed well-defined rounded hypo-dense non-enhancing homogenous mass devoid of necrosis/calcification in the region of left adrenal gland measuring $80 \times 78 \mathrm{~mm}$, indistinct from adrenal gland. Other abdominal, pelvic and urogenital organs were normal except for contracted GB with few tiny calculi in lumen.

MRIT2 weighted image showed well-defined encapsulated heterogeneously enhancing left adrenal mass measuring $77 \times 72$ $\mathrm{mm}$ with delayed contrast washout, causing mild compression of underlying LK upper pole without invading it (Figure 1). Right kidney and adrenal were normal, lymphadenopathy was absent. Clinical impression was benign left adrenal gland tumor.

Laparoscopic adrenalectomy was performed to remove Nonadenomatous lesion and sent for histopathology evaluation. Gross examination revealed adrenal gland with tumor weighing

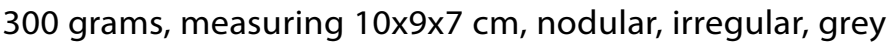
colored, congested and partially covered with fatty tissue. Cut section showed a well-encapsulated tumor with homogenous grey appearance (Figure 2). Microscopy examination revealed normal adrenal cortical and medullary tissue with adjacent well-encapsulated benign tumor of mature ganglion cells and 


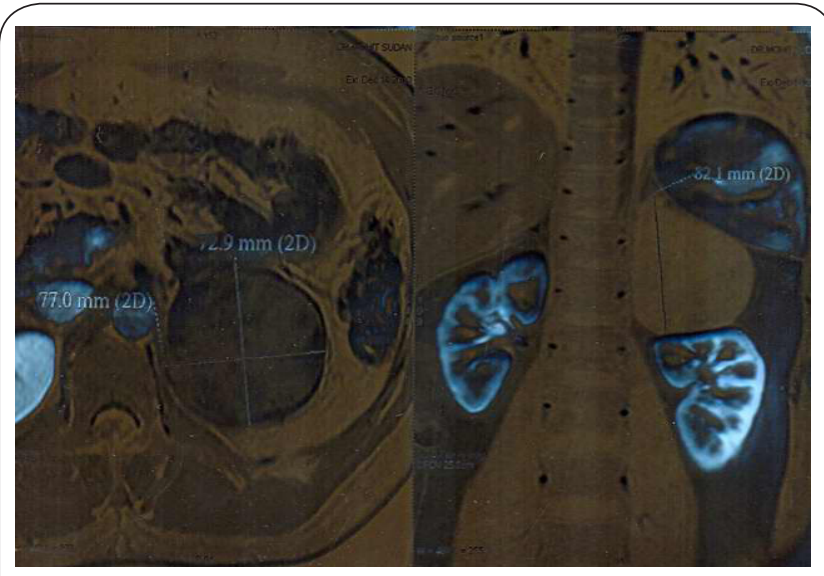

Figure 1. MRI T2 weighted image showed well-defined encapsulated left adrenal mass (demarcated by line) (left side), causing mild compression of underlying LK upper pole without invading it (on right side).

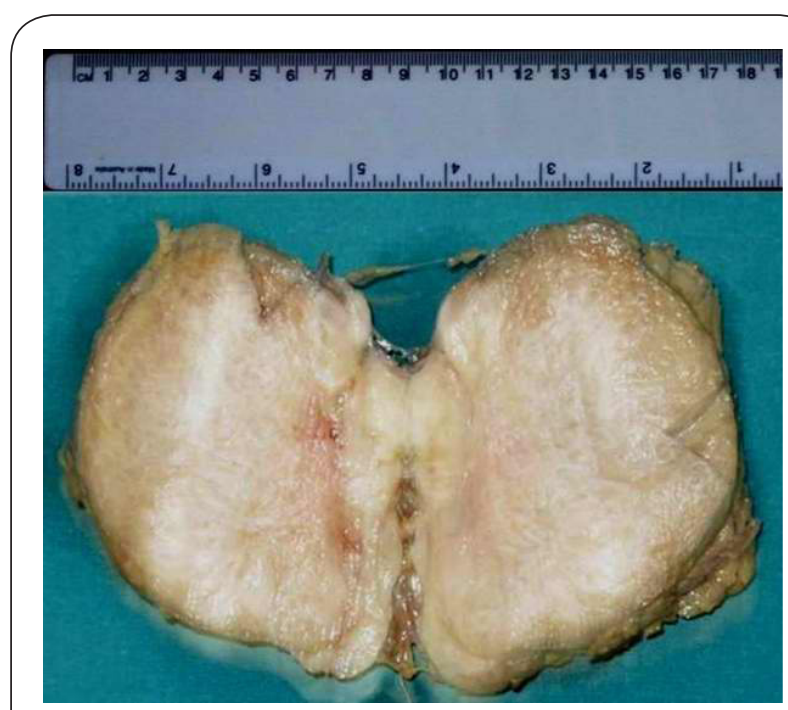

Figure 2. Gross specimen of adrenal gland tumor with homogenous grey appearance.

Schwann cells arranged in fascicles (Figure 3), staining strongly with neuron-specific enolase and s-100 proteins (Figure 4). No immature cells/malignancy was noted. Final diagnosis of ganglioneuroma (mature type) of adrenal gland was made. After one year of follow-up, the patient is asymptomatic.

\section{Discussion}

Adrenal GN is uncommon tumor. To our knowledge there are totally less than 500 adrenal GN reported in the world literature. Tumors arising from neural crest cells including sympathetic ganglia and adrenal medulla comprise pheochromocytoma/ paraganglioma, neuroblastomas, ganglioneuroblastoma and GN. These are "functional" i.e., catecholamine-producing or "non-functional". GNs are supposed have low or no metabolic

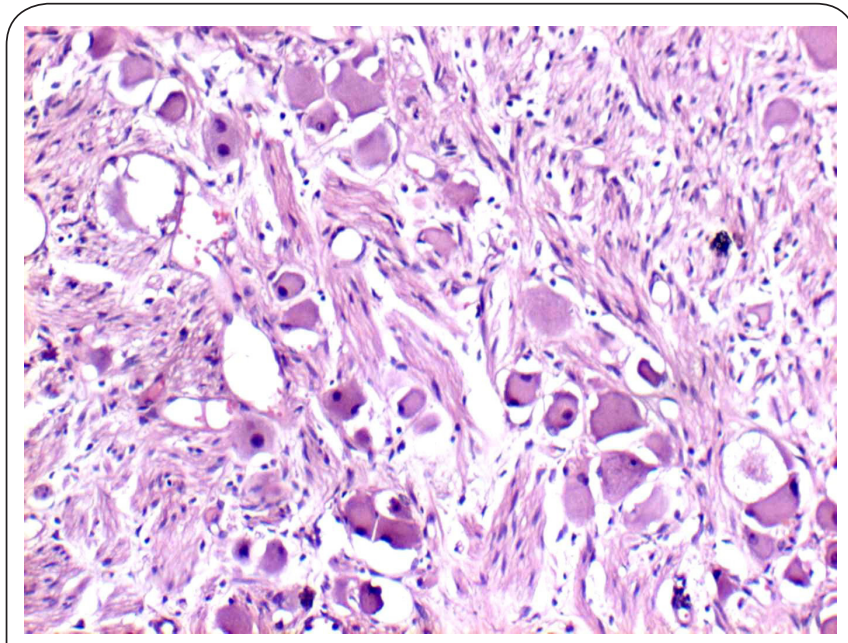

Figure 3. H\&E section showing mature ganglion cells and Schwann cells arranged in fascicles.

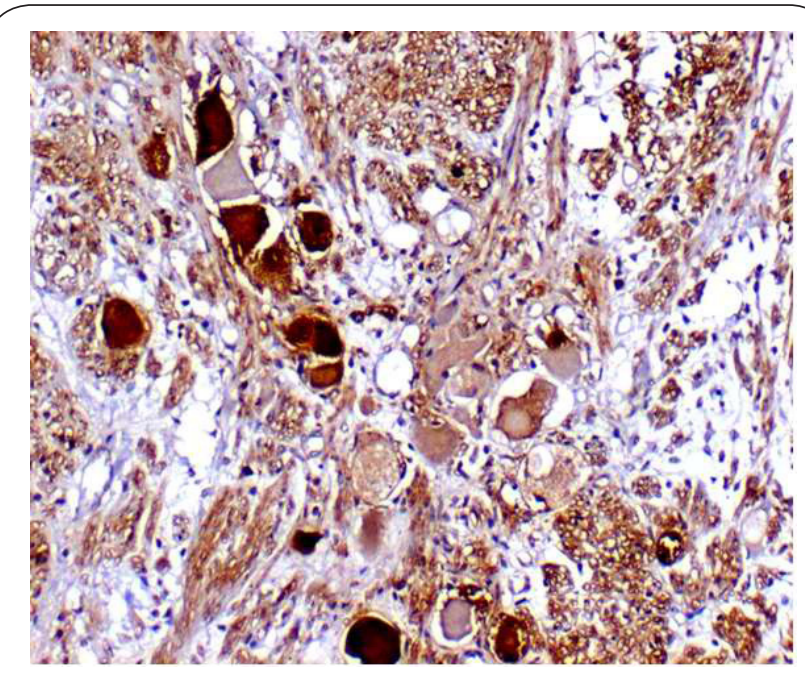

Figure 4. Immunohistochemistry showing mature ganglion cells and Schwann cells staining strongly with neuron-specific enolase.

activity. The most common location of $\mathrm{GN}$ includes posterior mediastinum and retroperitoneum; only a small proportion of GNs are adrenal in origin. Adrenal GN is more frequent in chidren $\& 4^{\text {th }} / 5^{\text {th }}$ decade of life unlike our patient who was in his 30s. The most common site of $\mathrm{GN}$ are retroperitonum (32-52\%), mediastinal (39-43\%), or cervical region (8-9\%) and only rarely in adrenal gland $[5,6]$.

Their serendipitous presentation makes diagnosis difficult and catches the treating physician by surprise. It is usually asymptomatic and hormonally silent. Though GN synthesizes catecholamines, it rarely causes hypertension and is incidentally detected on imaging studies for unrelated symptoms. However some patients do present with epigastric/ abdominal pain with diarrhea, vomiting and hypertension as 
was noted in our patient $[1,7]$. Incidentally our patient had associated gall stones and hence calculus cholecystitis was suspected. Long term studies in Chinese population showed 180 incidental adrenal tumors resected, out of which $17(9.4 \%)$ were diagnosed as adrenal GN [3]. Increasing number of these tumors are being found incidentally by USG/CT/MRI especially in asymptomatic cases. Malignant transformation is rarely reported. It needs careful evaluation \& surgical resection is the choice of therapy for such tumors $[2,3,8]$.

\section{Conclusion}

To conclude, adrenal GN is a rare serendipitous tumor, which is extremely uncommon in adults. It can mimick chronic calculus cholecystitis and definite diagnosis can be established only after histological examination of the resected tumor.

\section{List of abbreviations \\ GB: Gall bladder \\ GN: Ganglioneuroma \\ LK: Left kidney}

\section{Competing interests}

The authors declare that they have no competing interests.

\section{Authors' contributions}

RDP Major contributor in writing the manuscript, analysis and interpretation of patient data regarding the histopathological disease. AVVPerformed the histological examination and helped in preparation of the final manuscript. HLTClinical \& post operative follow up of patient.

\section{Acknowledgement}

We are indebted to Ms. Jyotsana Suthar and Ms. Yogita Tirgar for providing literature search, typing, preparing the manuscript and Submission. The authors thank the staff and technicians of IKDRCITS, India, for all the technical help.

\section{Publication history}

Received: 02-Apr-2013 Revised: 14-May-2013

Accepted: 10-Jun-2013 Published: 23-Jul-2013

\section{References}

1. Leavitt JR, Harold DL and Robinson RB. Adrenal ganglioneuroma: a familial case. Urology. 2000; 56:508. | Article I PubMed

2. Qing $Y$, Bin $X$, Jian $W$, Li G, Linhui $W$, Bing $L$, Huiqing $W$ and Yinghao $S$. Adrenal ganglioneuromas: a 10-year experience in a Chinese population. Surgery. 2010; 147:854-60. | Article | PubMed

3. Maweja S, Materne R, Detrembleur N, de Leval L, Defechereux T, Meurisse $M$ and Hamoir E. Adrenal ganglioneuroma. Am J Surg. 2007; 194:683-4. I Article I PubMed

4. Rha SE, Byun JY, Jung SE, Chun HJ, Lee HG and Lee JM. Neurogenic tumors in the abdomen: tumor types and imaging characteristics. Radiographics. 2003; 23:29-43. I Article I PubMed

5. Erem C, Ucuncu O, Nuhoglu I, Cinel A, Cobanoglu U, Demirel A, Koc E, Kocak $M$ and Guvendi GF. Adrenal ganglioneuroma: report of a new case. Endocrine. 2009; 35:293-6. I Article I PubMed

6. Arredondo Martinez F, Soto Delgado M, Benavente Fernandez A, Basquero Gonzalez B, Zurera Cosano A and Linares Armada R. [Adrenal ganglioneuroma. Report of a new case]. Actas Urol Esp. 2003; 27:221-5. I PubMed

7. Geoerger B, Hero B, Harms D, Grebe J, Scheidhauer K and Berthold F. Metabolic activity and clinical features of primary ganglioneuromas.
Cancer. 2001; 91:1905-13. | Article | PubMed

8. Oderda M, Cattaneo E, Soria F, Barreca A, Chiusa L, Morelli B, Zitella A and Gontero $P$. Adrenal ganglioneuroma with multifocal retroperitoneal extension: a challenging diagnosis. ScientificWorldJournal. 2011; 11:1548-53. | Article | PubMed Abstract | PubMed Full Text

\section{Citation:}

Patel RD, Vanikar AV and Trivedi HL: Non-functional adrenal gland ganglioneuroma: case report. Res J Endocrinol Metab 2013, 1:1. http://dx.doi.org/10.7243/2053-3640-1-1 